\title{
A WEIBULL FAILURE MODEL TO THE STUDY OF THE HIERARCHICAL BAYESIAN RELIABILITY
}

\section{MODEL USZKODZEŃ APROKSYMOWANY ROZKŁADEM WEIBULLA DO BADANIA NIEZAWODNOŚCI REPREZENTOWANEJ ZA POMOCA HIERARCHICZNEJ SIECI BAYESOWSKIEJ}

\begin{abstract}
This paper describes the unknown parameter and reliability function of the Weibull distribution based on hierarchical Bayesian model for the progressively Type-II censored data. The scale parameter of the Weibull distribution is considered with a gamma prior under the shape parameter is known. Furthermore, the scale parameter of the gamma prior is assumed to be three different known hyper prior. Under these assumptions, the Weibull parameter and reliability function estimators are derived based on the squared error loss (SEL) function, which can be easily extended to other loss functions situation. The result from hierarchical Bayesian method is used to compare with Bayes and maximum likelihood estimate (MLE) methods. The simulation shown that the results from Bayes is the best, followed by hierarchical Bayesian method, and then MLE in terms of root mean square error (RMSE). Finally, one real dataset has been analyzed for illustrative purposes.
\end{abstract}

Keywords: Hierarchical Bayesian model, Progressive Type-II censoring, Hyper parameter, Monte Carlo simulation, Parameter estimation.

\begin{abstract}
W prezentowanej pracy opisano metodę estymacji nieznanego parametru oraz funkcji niezawodności rozkładu Weibulla w oparciu o hierarchiczny model Bayesa dla danych uciętych (cenzurowanych) progresywnie typu II. Rozważano parametr skali rozktadu Weibulla o rozkładzie prawdopodobieństwa apriorycznego gamma w sytuacji, gdzie wartość parametru ksztaltu była znana. Ponadto, przyjęto, że (hiper)parametr skali rozkladu apriorycznego gamma może mieć trzy różne, znane hiper-rozkłady aprioryczne (ang. hyper priors). Przy tych założeniach, estymatory parametru i funkcji niezawodności rozkladu Weibulla wyprowadzono na podstawie kwadratowej funkcji straty (ang. squared error loss, SEL), którą można łatwo rozszerzyć na inne funkcje straty. Wyniki otrzymane z wykorzystaniem hierarchicznej metody Bayesowskiej porównano z wynikami klasycznej estymacji Bayesowskiej oraz estymacji metoda największego prawdopodobieństwa (ang. maximum likelihood estimate, MLE). Symulacja wykazała, że najlepsze wyniki, jeśli chodzi o średnia kwadratowa btędów (ang. root mean squared error, RMSE), daje metoda Bayesa, a w dalszej kolejności hierarchiczna metoda Bayesa oraz MLE. W końcowej części pracy rozważane problemy zilustrowano analizując zbiór danych rzeczywistych.
\end{abstract}

Stowa kluczowe: hierarchiczny model bayesowski, ucinanie progresywne typu II, hiperparametr, symulacja Monte Carlo, estymacja parametrów.

\section{Introduction}

The Weibull distribution was introduced by the Swedish physicist Weibull [17], it has been used in many different fields like material science, engineering, physics, chemistry, meteorology, medicine, pharmacy, economics and business, quality control, biology, geology and geography, see for example [14]. The two parameters Weibull distribution is one of the most widely used lifetime models in reliability and survival analysis because of its various shapes of the probability density function(pdf) and its convenient representation of the survival function. In any practical situation, however, the parameters of the Weibull model cannot be known with certainly, especially if the available data are sparse. The estimation of its parameters has been discussed by a number of authors: see for example, Zakerzadeh and Jafari [18], Wang and Ye [16], Doostparast [8]. During the recent several years a number of papers have adopted the Bayesian approach to dealt with the uncertainty about the parameter by different prior distribution for example, see Soland [15], Kaminskiy and Krivtsov [9], Berger and Sun [6] and Kundu and Joarder [12] and Kundu [11] among others.
In particular, Kundu [11] studied the Weibull distribution as a failure model from the Bayesian approach, by considering gamma prior for the scale parameter when the shape parameter is known.

In this study, the scale parameter of the Weibull failure model will be discussed when the shape parameter is known. The scale parameter is considered a random variable with a $\operatorname{Gamma}(a, b)$ distribution as a prior. Further more the hyper parameter $b$ of $\operatorname{Gamma}(a, b)$ cannot be specified but one is willing to assign a hyper prior distribution. Specifically three hyper prior distributions for the scale hyper parameter $b$ will be considered, a uniform, a truncated exponential and an improper prior. Aforementioned three hyper prior were discussed by Alex [3] based on complete sample for exponential failure model. Using these hyper prior, we developed a class of method based on censored sample under hierarchical Bayesian model. Although extensive work has been done on the statistical inferences of the unknown parameters of the Weibull distribution for censored sample data in the Bayesian context, but not much work has been done for censored sample data in the hierarchical Bayesian set up. Among the different censoring schemes 
Type-I and Type-II are the two most popular. In the last few years, the progressive Type-II censoring scheme has been received considerable attention, see the book by Balakrishnan and Aggrawala[4] and also there are excellent review article by Balakrishnan[5].

The progressive Type-II censoring scheme can be briefly described as follows. Suppose that $n$ identical units are put on test. The integer $m<n$ is pre-fixed and also $R_{1}, \cdots, R_{m}$ are $m$ pre-fixed non-negative integers such that $R_{1}+\cdots+R_{m}+m=n$. At the time of the first failure $t_{1}, R_{1}$ of the remaining units are randomly removed. Similarly, at the time of the second failure $t_{2}, R_{2}$ of the remaining units are removed and so on. Finally, at the time of the $m$-th failure the rest of the $R_{m}=n-R_{1}-\cdots-R_{m-1}-m$ units are removed. Note that the usual Type-II censoring scheme can be obtained as a special case of the progressive censoring scheme, simply by taking $R_{1}=\cdots=R_{m-1}=0$.

The rest of the paper is organized as follows. In the next Section, the Bayesian and MLEs of the unknown parameter and reliability function are presented. In Section 3, we introduce three hyper priors to construct the hierarchical Bayesian estimators for the unknown parameter and reliability function. Two simulation datasets have been analyzed in Section 4. A real dataset is analyzed for illustration in Section 5. Finally, conclusions appear in Section 6.

\section{Maximum likelihood and Bayesian estimates}

A random variable $X$ follows the Weibull distribution with parameters $\alpha$ and $\lambda$, and is denoted by $X \sim W E(\alpha, \lambda)$. Its probability density function (pdf) is that:

$$
f(x ; \alpha, \lambda)=\alpha \lambda \mathrm{e}^{-\lambda x^{\alpha}} x^{\alpha-1}, x>0 .
$$

Then the reliability function of $X$ is given by $R(x ; \alpha, \lambda)=\mathrm{e}^{-\lambda x^{\alpha}}$, where $\alpha>0$ and $\lambda>0$ are the shape and scale parameters respectively. In the case of progressive Type-II censored data, let $m(1<m \leq n)$ denote the number of observed failures and $x_{1}, \cdots, x_{m}$ denote the progressive Type-II censored sample, when $\alpha$ is known, the likelihood function:

$$
L(\lambda ; \text { data }) \propto \lambda^{m} \mathrm{e}^{-\lambda T}
$$

where $T=\sum_{i=1}^{m}\left(R_{i}+1\right) x_{i}^{\alpha}$. The differential equation of the logarithm likelihood function based on progressive Type-II censored sample is:

$$
\frac{d \ln L}{d \lambda}=\frac{m}{\lambda}-\sum_{i=1}^{m}\left(R_{i}+1\right) x_{i}^{\alpha}=0
$$

Eq.(3) readily yields a closed-form expression for the MLE of $\lambda$ as follows:

$$
\hat{\lambda}=\frac{m}{T}
$$

Furthermore, we derived MLE for the reliability function given as $\hat{R}(x)=\mathrm{e}^{-\hat{\lambda} x^{\alpha}}$. And we assume that $\lambda$ has a gamma prior distribution with pdf $\pi(\lambda \mid a, b)=\frac{b^{a}}{\Gamma(a)} \lambda^{a-1} \mathrm{e}^{-b \lambda}, \lambda>0$, the hyper parameters $a>0, b>0$, and $\Gamma(a)=\int_{0}^{\infty} x^{a-1} \mathrm{e}^{-x} d x$. The posterior distribution of $\lambda$, given the data and the hyper parameters $a$ and $b$, is $\operatorname{Gamma}(a+m, b+T)$ [11]. Therefore, the Bayesian estimators of $\lambda$ and $R(x)$ with respect to SEL function are:

$$
\hat{\lambda}_{0}=E(\lambda \mid \text { data })=\frac{a+m}{b+T},
$$

where $E$ is operator of expected value, and:

$$
\hat{R}_{0}(x)=E(R(x) \mid \text { data })=\left(\frac{b+T}{b+T+x^{\alpha}}\right)^{a+m} .
$$

\section{Hierarchical Bayesian model}

In the section 2, we obtain the Bayesian estimators of $\lambda$ and $R(x)$ when gamma prior parameters are known. In this section, we will consider the hierarchical Bayesian estimators when the hyper parameter $a$ is known but the hyper parameter $b$ behaves as a random variable.

\subsection{Uniform prior for the hyper parameter $b$}

Suppose unknown hyper parameter $b$ in the prior $\operatorname{Gamma}(a, b)$ follows uniform distribution with pdf:

$$
\pi_{1}(b)=\frac{1}{d-c}, \quad 0 \leq c<d
$$

The parameters $c$ and $d$ are assumed to be known. From $\operatorname{Gamma}(a, b)$ and (4), the prior of $\lambda$ is:

$$
g_{1}(\lambda)=\frac{1}{d-c} \int_{c}^{d} \frac{b^{a}}{\Gamma(a)} \lambda^{a-1} \mathrm{e}^{-b \lambda} d b
$$

Under the $W E(\alpha, \lambda)$ model from (1), the likelihood function of the progressive Type-II censored data is proportion to (2). This likelihood is combined with the prior (5) via Bayesian theorem to obtain the $\lambda$ posterior pdf:

$$
h_{1}(\lambda \mid \text { data }) \propto g_{1}(\lambda) L(\lambda ; \text { data }) \propto \lambda^{m} \mathrm{e}^{-\lambda T} \frac{1}{d-c} \int_{c}^{d} \frac{b^{a}}{\Gamma(a)} \lambda^{a-1} \mathrm{e}^{-b \lambda} d b .
$$

Under SEL function, the hierarchical Bayesian estimators of $\lambda$ and $R(x)$ are given by:

$$
\hat{\lambda}_{1}=E(\lambda \mid \text { data })=\frac{m+a}{T} \frac{B_{d / d+T}(a+1, m)-B_{c / c+T}(a+1, m)}{B_{d / d+T}(a+1, m-1)-B_{c / c+T}(a+1, m-1)}
$$

and:

$\hat{R}_{1}(x)=E(R(x) \mid$ data $)=\left(\frac{T}{T+x^{\alpha}}\right)^{m-1} \frac{B_{d / d+T+x^{\alpha}}(a+1, m-1)-B_{c / c+T+x^{\alpha}}(a+1, m-1)}{B_{d / d+T}(a+1, m-1)-B_{c / c+T}(a+1, m-1)}$ 
respectively. Here $B_{x}(i, j)=\int_{0}^{x} t^{i-1}(1-t)^{j-1} d t$ denotes the incomplete beta function (see, Abramwitz and Stegun[2]).

\subsection{Truncated exponential prior for $\boldsymbol{b}$}

Suppose that the prior distribution for the hyper parameter $b$ is a truncated exponential distribution given by conditional probability density function:

$$
\pi_{2}(b \mid u, v, \theta)=c_{1} \mathrm{e}^{-\theta b}, \quad u \leq b \leq v, \theta>0,
$$

where $c_{1}=\theta /\left(\mathrm{e}^{-\theta u}-\mathrm{e}^{-\theta v}\right)$ and $u>0$, using the same procedure as previously, we obtain the prior pdf of $\lambda$ :

$$
g_{2}(\lambda)=\int_{u}^{v} \frac{\theta \mathrm{e}^{-\theta b}}{\mathrm{e}^{-\theta u}-\mathrm{e}^{-\theta v}} \frac{b^{a}}{\Gamma(a)} \lambda^{a-1} \mathrm{e}^{-b \lambda} d b
$$

and posterior pdf of $\lambda$ :

$h_{2}(\lambda \mid$ data $) \propto g_{2}(\lambda) L(\lambda ;$ data $) \propto \lambda^{m} \mathrm{e}^{-\lambda T} \int_{u}^{v} \frac{\theta \mathrm{e}^{-\theta b}}{\mathrm{e}^{-\theta u}-\mathrm{e}^{-\theta v}} \frac{b^{a}}{\Gamma(a)} \lambda^{a-1} \mathrm{e}^{-b \lambda} d b$

The Bayesian estimators for the parameter $\lambda$ and reliability function $R(x)$ are given by:

$$
\hat{\lambda}_{2}=E(\lambda \mid \text { data })=(m+a) \frac{\int_{u}^{v} b^{a}(b+T)^{-(m+a+1)} \mathrm{e}^{-\theta b} d b}{\int_{u}^{v} b^{a}(b+T)^{-(m+a)} \mathrm{e}^{-\theta b} d b}
$$

and

$$
\hat{R}_{2}(x)=E(R(x) \mid \text { data })=\frac{\int_{u}^{v} b^{a}\left(b+T+x^{\alpha}\right)^{-(m+a)} \mathrm{e}^{-\theta b} d b}{\int_{u}^{v} b^{a}(b+T)^{-(m+a)} \mathrm{e}^{-\theta b} d b}
$$

respectively.

Unfortunately the estimators in (6) and (7) are not in closed form and numerical technique have to be utilized in evaluating the integrals involved.

\subsection{Improper prior for $b$}

Let the prior for $b$ be:

$$
\pi_{3}(b) \propto \frac{1}{b}, \quad 0<b<\infty
$$

from $\operatorname{Gamma}(a, b)$ and (8), the prior of $\lambda$ is:

$$
g_{3}(\lambda)=\int_{0}^{\infty} \frac{1}{b} \frac{b^{a}}{\Gamma(a)} \lambda^{a-1} \mathrm{e}^{-b \lambda} d b
$$

Under the $W E(\alpha, \lambda)$ model from (1), the likelihood function of progressive Type-II censored data is proportion to (2). This likelihood is combined with the prior (9) via Bayesian theorem to obtain the $\lambda$ posterior pdf:

$$
h_{3}(\lambda \mid \text { data })=\frac{\lambda^{m-1} \mathrm{e}^{-\lambda T} T^{m}}{\Gamma(m)}, \lambda>0 .
$$

Under SEL function, the hierarchical Bayesian estimators of $\lambda$ and $R(x)$ are given by:

$$
\hat{\lambda_{3}}=E(\lambda \mid \text { data })=\frac{m}{T}
$$

and:

$$
\hat{R}_{3}(x)=E(R(x) \mid \text { data })=\frac{T^{m}}{\left(T+x^{\alpha}\right)^{m}}
$$

respectively.

\section{Simulation study}

In this section, we present experimental results to observe the behavior of the proposed method for different sample sizes $(n)$, different effective sample sizes $(m)$, different priors and for the different progressive Type-II censoring schemes. We have considered sample sizes $(n=20,30,50)$, effective sample sizes $(m=15,20,35)$, and nine censoring schemes. Details of the schemes are given in Table 1.

Special sample schemes were simulated from the $\operatorname{WE}(0.8,1)$ and $\operatorname{WE}(0.8,1.5)$. The average estimates for the parameter and the reliability function were computed from the generated progressively Type-II censored sample based on 1000 replications. In all cases, mainly to compare the MLEs, Bayesian estimates and different hierarchical Bayesian estimates of the unknown parameter $\lambda$ and some values of reliability function $R(x)$. We also compute the corresponding RMSEs of the estimates based on 1000 replications. Using the

\begin{tabular}{|c|c|c|c|}
\hline$n$ & $m$ & $R_{1}, \cdots, R_{m}$ & $\begin{array}{l}\text { Scheme } \\
\text { number }\end{array}$ \\
\hline \multirow[t]{3}{*}{20} & 15 & $R_{1}=\cdots=R_{14}=0, R_{15}=5$ & [1] \\
\hline & & $R_{1}=5, R_{2}=\cdots=R_{15}=0$ & [2] \\
\hline & & $R_{1}=\cdots=R_{5}=1, R_{6}=\cdots=R_{15}=0$ & [3] \\
\hline \multirow[t]{3}{*}{30} & 20 & $R_{1}=\cdots=R_{19}=0, R_{20}=10$ & [4] \\
\hline & & $R_{1}=10, R_{2}=\cdots=R_{20}=0$ & [5] \\
\hline & & $R_{1}=\cdots=R_{9}=0, R_{10}=R_{11}=5, R_{12}=\cdots=R_{20}=0$ & [6] \\
\hline \multirow[t]{3}{*}{50} & 35 & $R_{1}=\cdots=R_{34}=0, R_{35}=15$ & [7] \\
\hline & & $R_{1}=\cdots=R_{33}=0, R_{34}=5, R_{35}=10$ & [8] \\
\hline & & $R_{1}=\cdots R_{3}=5, R_{4}=\cdots=R_{35}=0$ & [9] \\
\hline
\end{tabular}
expression described in Section 2 and Section 3, we obtain MLEs, Bayesian and hierarchical Bayesian estimates of $\lambda$ and $R(x)$ in Table 2 from the $W E(0.8,1)$ and Table 3 from the $W E(0.8,1.5)$. For Bayesian estimates, we used parameter values $a=1, b=2$. For hierarchical Bayesian estimates, we using the Monte Carlo technique to compute hierarchical Bayesian estimates of the unknown parameter $\lambda$ as well as reliability function $R(x)$. The parameter $a$ 's value is also set
Table 1. Several censoring schemes for the simulation study 
Table 2. Average values of the estimators and their RMSEs when $\alpha=0.8, \lambda=1$ and $x=0.2$

\begin{tabular}{|c|c|c|c|c|c|c|c|c|c|c|c|}
\hline \multicolumn{2}{|c|}{ scheme } & \multicolumn{2}{|c|}{ MLEs } & \multicolumn{2}{|c|}{ Bayesian estimates } & \multicolumn{6}{|c|}{ Hierarchical Bayesian estimates } \\
\hline & & $\hat{\lambda}$ & $\hat{R}(x)$ & $\hat{\lambda}_{0}$ & $\hat{R}_{0}(\mathrm{x})$ & $\hat{\lambda}_{1}$ & $\hat{R}_{1}(x)$ & $\hat{\lambda}_{2}$ & $\hat{R}_{2}(x)$ & $\hat{\lambda}_{3}$ & $\hat{R}_{3}(x)$ \\
\hline \multirow[t]{2}{*}{ [1] } & Estimates & 1.1054 & 0.7411 & 1.0597 & 0.7504 & 1.1735 & 0.7569 & 1.0965 & 0.7430 & 1.0692 & 0.7490 \\
\hline & RMSEs & 0.3873 & 0.7400 & 0.2674 & 0.0500 & 0.2882 & 0.0524 & 0.2895 & 0.0568 & 0.2934 & 0.0568 \\
\hline \multirow[t]{2}{*}[2]{} & Estimates & 0.9959 & 0.7630 & 1.0640 & 0.7495 & 1.1781 & 0.7561 & 1.1010 & 0.7421 & 1.0737 & 0.7481 \\
\hline & RMSEs & 0.3439 & 0.0689 & 0.2659 & 0.0500 & 0.2867 & 0.0524 & 0.2884 & 0.0564 & 0.2909 & 0.0567 \\
\hline \multirow[t]{2}{*}{ [3] } & Estimates & 1.0115 & 0.7601 & 1.0636 & 0.7497 & 1.1777 & 0.7563 & 1.1014 & 0.7424 & 1.0737 & 0.7482 \\
\hline & RMSEs & 0.3686 & 0.0725 & 0.2753 & 0.0515 & 0.2967 & 0.0539 & 0.3004 & 0.0581 & 0.3022 & 0.0584 \\
\hline \multirow[t]{2}{*}{ [4] } & Estimates & 1.1138 & 0.7385 & 1.0400 & 0.7535 & 1.1226 & 0.7584 & 1.0660 & 0.7486 & 1.0451 & 0.7528 \\
\hline & RMSEs & 0.3417 & 0.0663 & 0.2377 & 0.0458 & 0.2515 & 0.0475 & 0.2521 & 0.0508 & 0.2533 & 0.0503 \\
\hline \multirow[t]{2}{*}[5]{} & Estimates & 0.9670 & 0.7679 & 1.0467 & 0.7520 & 1.1298 & 0.7569 & 1.0734 & 0.7471 & 1.0518 & 0.7512 \\
\hline & RMSEs & 0.2788 & 0.0567 & 0.2232 & 0.0430 & 0.2362 & 0.0445 & 0.2370 & 0.0470 & 0.2379 & 0.0472 \\
\hline \multirow[t]{2}{*}{ [6] } & Estimates & 1.0404 & 0.7532 & 1.0457 & 0.7523 & 1.1287 & 0.7572 & 1.0725 & 0.7473 & 1.0511 & 0.7515 \\
\hline & RMSEs & 0.3226 & 0.0634 & 0.2349 & 0.0449 & 0.2483 & 0.0466 & 0.2481 & 0.0499 & 0.2509 & 0.0494 \\
\hline \multirow[t]{2}{*}{ [7] } & Estimates & 1.0666 & 0.7466 & 1.0254 & 0.7552 & 1.0711 & 0.7581 & 1.0397 & 0.7530 & 1.0271 & 0.7550 \\
\hline & RMSEs & 0.2434 & 0.0485 & 0.1793 & 0.0356 & 0.1852 & 0.0363 & 0.1851 & 0.0384 & 0.1856 & 0.0375 \\
\hline \multirow[t]{2}{*}{ [8] } & Estimates & 1.0698 & 0.7459 & 1.0276 & 0.7547 & 1.0734 & 0.7576 & 1.0428 & 0.7523 & 1.0293 & 0.7545 \\
\hline & RMSEs & 0.2358 & 0.0474 & 0.1742 & 0.0348 & 0.1799 & 0.0355 & 0.1810 & 0.0375 & 0.1799 & 0.0366 \\
\hline \multirow[t]{2}{*}{ [9] } & Estimates & 0.9346 & 0.7739 & 1.0279 & 0.7547 & 1.0736 & 0.7575 & 1.0426 & 0.7521 & 1.0296 & 0.7544 \\
\hline & RMSEs & 0.2139 & 0.0441 & 0.1761 & 0.0348 & 0.1818 & 0.0355 & 0.1832 & 0.0372 & 0.1824 & 0.0367 \\
\hline
\end{tabular}

Table 3. Average values of the estimators and their RMSEs when $\alpha=0.8, \lambda=1.5$ and $x=0.1$

\begin{tabular}{|c|c|c|c|c|c|c|c|c|c|c|c|}
\hline \multicolumn{2}{|c|}{ Scheme } & \multicolumn{2}{|c|}{ MLEs } & \multicolumn{2}{|c|}{ Bayesian estimates } & \multicolumn{6}{|c|}{ Hierarchical Bayesian estimates } \\
\hline & & $\hat{\lambda}$ & $\hat{R}(x)$ & $\hat{\lambda}_{0}$ & $\hat{R}_{0}(\mathrm{x})$ & $\hat{\lambda}_{1}$ & $\hat{R}_{1}(x)$ & $\hat{\lambda}_{2}$ & $\hat{R}_{2}(x)$ & $\hat{\lambda}_{3}$ & $\hat{R}_{3}(x)$ \\
\hline \multirow[t]{2}{*}{ [1] } & Estimates & 1.8804 & 0.7460 & 1.5633 & 0.7834 & 1.7136 & 0.7911 & 1.6523 & 0.7730 & 1.6359 & 0.7752 \\
\hline & RMSES & 0.6528 & 0.0723 & 0.3752 & 0.0421 & 0.3991 & 0.0447 & 0.4304 & 0.0515 & 0.4439 & 0.0516 \\
\hline \multirow[t]{2}{*}{ [2] } & Estimates & 1.6646 & 0.7715 & 1.5477 & 0.7854 & 1.6967 & 0.7930 & 1.6346 & 0.7750 & 1.6190 & 0.7774 \\
\hline & RMSEs & 0.6058 & 0.0706 & 0.3933 & 0.0444 & 0.4187 & 0.0471 & 0.4487 & 0.0535 & 0.4624 & 0.0542 \\
\hline \multirow[t]{2}{*}{ [3] } & Estimates & 1.6658 & 0.7712 & 1.5318 & 0.7872 & 1.6779 & 0.7947 & 1.6165 & 0.7770 & 1.5995 & 0.7796 \\
\hline & RMSEs & 0.5957 & 0.0682 & 0.3734 & 0.0420 & 0.3974 & 0.0446 & 0.4291 & 0.0503 & 0.4413 & 0.0514 \\
\hline \multirow[t]{2}{*}{ [4] } & Estimates & 1.8717 & 0.7463 & 1.5343 & 0.7863 & 1.6433 & 0.7921 & 1.5965 & 0.7789 & 1.5831 & 0.7807 \\
\hline & RMSEs & 0.5847 & 0.0637 & 0.3375 & 0.0385 & 0.3532 & 0.0403 & 0.3745 & 0.0449 & 0.3840 & 0.0449 \\
\hline \multirow[t]{2}{*}{ [5] } & Estimates & 1.0657 & 0.7772 & 1.5341 & 0.7862 & 1.6431 & 0.7920 & 1.5971 & 0.7790 & 1.5819 & 0.7806 \\
\hline & RMSES & 0.4569 & 0.0543 & 0.3131 & 0.0362 & 0.3279 & 0.0379 & 0.3431 & 0.0425 & 0.3516 & 0.0420 \\
\hline \multirow[t]{2}{*}{ [6] } & Estimates & 1.7126 & 0.7645 & 1.5213 & 0.7878 & 1.6296 & 0.7935 & 1.5801 & 0.7800 & 1.5677 & 0.7824 \\
\hline & RMSES & 0.4943 & 0.0578 & 0.3159 & 0.0366 & 0.3309 & 0.0383 & 0.3448 & 0.0430 & 0.3542 & 0.0424 \\
\hline \multirow[t]{2}{*}[7]{} & Estimates & 1.7639 & 0.7575 & 1.5110 & 0.7883 & 1.5710 & 0.7916 & 1.5440 & 0.7840 & 1.5353 & 0.7853 \\
\hline & RMSES & 0.3879 & 0.0458 & 0.2530 & 0.0303 & 0.2596 & 0.0311 & 0.2655 & 0.0335 & 0.2687 & 0.0329 \\
\hline \multirow[t]{2}{*}[8]{} & Estimates & 1.7607 & 0.7579 & 1.5095 & 0.7885 & 1.5695 & 0.7918 & 1.5431 & 0.7850 & 1.5338 & 0.7856 \\
\hline & RMSES & 0.3990 & 0.0483 & 0.2574 & 0.0305 & 0.2640 & 0.0314 & 0.2703 & 0.0342 & 0.2745 & 0.0332 \\
\hline \multirow[t]{2}{*}[9]{} & Estimates & 1.5706 & 0.7808 & 1.5324 & 0.7856 & 1.5930 & 0.7891 & 1.5666 & 0.7818 & 1.5582 & 0.7826 \\
\hline & RMSEs & 0.3565 & 0.0430 & 0.2603 & 0.0309 & 0.2670 & 0.0317 & 0.2744 & 0.0347 & 0.2776 & 0.0336 \\
\hline
\end{tabular}

to 1. The hyper parameter settings are as follows: the first is uniform prior: $c=1, d=2$; the second prior is truncated exponential distribution, for the second hyper prior, we have used the hyper parameters value as $u=0, v=1, \theta=1$; the third prior is improper prior.

Table 2 and Table 3 show that as effective sample size increases, the RMSEs of hierarchical Bayesian estimates decrease as well as Bayesian and MLEs. As far as $\lambda$ and $R(x)$, the performance of Bayesian estimation is better than MLE in terms of RMSE. Experimental results indicate that the hierarchical Bayesian estimates for the reliability function $R(x)$ and parameter $\lambda$ are better than the ones obtained for the maximum likelihood in the sense that they have smaller RMSEs. However, the hierarchical Bayesian estimates for the reliability function $R(x)$ and parameter $\lambda$ are worse slightly than the Bayesian estimates due to uncertainty of $b$. Three different hyper priors were performed for the robustness of the hierarchical Bayesian estimators, no matter which one we think is right, others "wrong" hyper priors will get approximate RMSEs.

\section{Application to real life data}

In this section, we present a real dataset to further illustrate the performance of the method proposed in this article. The dataset is the results of tests on endurance of deep groove ball bearings.

For illustrative the purposes, we applied the real dataset of $23 \mathrm{ob}-$ served failure times that was initially reported in Lieblein and Zelen [13] and later by a number of authors including Abouammoh and Alshingiti [1] and Krishna and Kumar [10]. Deya et al. [7] indicated that Weibull distribution fits this dataset better than the exponential, inverted exponential and gamma distribution. The following dataset represents the number of millions of revolutions before failure for each of the 23 ball bearings in a life test. 
Table 4. Average values of the estimators and the corresponding RMSEs based on real data and $x=50$

\begin{tabular}{|c|c|c|c|c|c|c|c|c|c|c|}
\hline \multirow[t]{2}{*}{$R C$ Scheme } & \multicolumn{2}{|c|}{ MLEs } & \multicolumn{2}{|c|}{ Bayesian estimates } & \multicolumn{6}{|c|}{ Hierarchical Bayesian estimates } \\
\hline & $\hat{\lambda}$ & $\hat{R}(x)$ & $\hat{\lambda}_{0}$ & $\hat{R}_{0}(\mathrm{x})$ & $\hat{\lambda}_{1}$ & $\hat{R}_{1}(x)$ & $\hat{\lambda}_{2}$ & $\hat{R}_{2}(x)$ & $\hat{\lambda}_{3}$ & $\hat{R}_{3}(x)$ \\
\hline Estimates & $8.9646 \mathrm{e}-7$ & 0.7961 & $7.0363 e-7$ & 0.8363 & $7.4272 \mathrm{e}-7$ & 0.8363 & $7.0357 e-7$ & 0.8362 & $7.0363 e-7$ & 0.8363 \\
\hline RMSEs & $4.3901 \mathrm{e}-4$ & 0.0319 & $1.5265 \mathrm{e}-7$ & 0.0303 & $1.6113 e-7$ & 0.0313 & $1.5364 \mathrm{e}-7$ & 0.0313 & $1.5265 \mathrm{e}-7$ & 0.0314 \\
\hline
\end{tabular}

$17.88,28.92,33.0,41.52,42.12,45.60,48.40,51.84,51.96$, $54.12,55.56,67.80,68.64,68.64,68.88,84.12,93.12,98.64$, $105.12,105.84,127.92,128.04,173.4$.

Deya et al.[7] obtained the MLEs of the parameters as: $(\alpha, \lambda)=(3.1835,1.4329 \mathrm{e}-6)$ based on hybrid censored sample generated from the same dataset. In our study, we generate a progressively type-II censored sample from the above dataset, with $m=19$, $n=23$ and the censoring scheme $R_{8}=2, R_{11}=1, R_{17}=1, R_{i}=0$, $i \neq 8,11,17$, and is denoted scheme $R C$. For computing different estimators, we assume that $\alpha=3.1835 ; a=b=0 ; c=0, d=20$ . We used the same 1000 replicates to compute different estimates and RMSEs for this scheme. The results of the MLEs, Bayesian estimates and hierarchical Bayesian estimates are reported in Table 4. The estimates results show that the Bayesian estimators are better than the hierarchical Bayesian estimators which in turn is better than the MLEs (in terms of RMSEs), as expected.

\section{Conclusion}

This paper takes into account the estimates of the unknown parameter and reliability function of Weibull distribution when the data are progressively type-II censored. The maximum likelihood estimation is considered as a part of frequentist statistics. The Bayesian inference of the unknown parameter and reliability function based on square error loss function are obtained. If prior distribution is unknown for the hyper parameter, the hierarchical Bayesian technique can be a better alternative to evade such circumstances to certificate robust of the hierarchical Bayesian estimation. We consider three different hyper priors, the resulting are closed to Bayesian estimates based on simulation samples and real life data, and outperforms the maximum likelihood estimates according to the root mean squared error function. Numerical experiments results show that the proposed method is feasible and effective. Hence, we can utilize hierarchical Bayesian method to analyze the progressively censored lifetime data especially when prior parameter information is not enough or even unknown.

\section{Acknowledgement}

The authors would like to thank the reviewers and the editors who helped to substantially improve the paper. The research work is supported by National Natural Science Foundation of China (11361036; 11461051), the Joint Specialized Research Fund for the Doctoral Program of Higher Education, Inner Mongolia Education Department (20131514110005), Higher School Science Research Project of Inner Mongolia (NJZY16394), Natural Science Foundation of Inner Mongolia (2014MS0112) and Science Research Project of Inner Mongolia University of Technology (ZD201409).

\section{References}

1. Abouammoh A M, Alshingiti A M. Reliability of generalized inverted exponential distribution. Journal of Statistical Computation and Simulation 2009; 79: 1301-1315, http://dx.doi.org/10.1080/00949650802261095.

2. Abramowitz M, Stegun A. Handbook of mathematical functions. Dover Publications, 1970.

3. Alex G P. A hierarchical approach to the study of the exponential failure model. Communications in Statistics-Theory and Methods 1989; 18(12): 4375-4392, http://dx.doi.org/10.1080/03610928908830161.

4. Balakrishnan N, Aggrawala R. Progressive censoring, theory, methods and applications. Birkhauser, Boston, 2000, http://dx.doi. org/10.1007/978-1-4612-1334-5.

5. Balakrishnan N. Progressive censoring methodology: An appraisal, Test 2007; 16(2): 211-296, http://dx.doi.org/10.1007/s11749-0070061-y.

6. Berger J O, Sun D. Bayesian analysis for the poly-Weibull distribution. Journal of the American Statistical Association 1993; 88: 1412-1418, http://dx.doi.org/10.1080/01621459.1993.10476426.

7. Deya S, Pradhan B. Generalized inverted exponential distribution under hybrid censoring. Statistical Methodology 2014; 18: 101-114, http:// dx.doi.org/10.1016/j.stamet.2013.07.007.

8. Doostparast M. Record-based inference and associated coast analysis for the Weibull distribution. Control and Cybernetics 2015; 44(1): 163177.

9. Kaminskiy M P, Krivtsov V V. A simple procedure for bayesian estimation of the Weibull distribution. IEEE Transactions on Reliability Analysis 2005; 54: 612-616, http://dx.doi.org/10.1109/TR.2005.858093.

10. Krishna H, Kumar K. Reliability estimation in generalized inverted exponential distribution with progressively type-II censored sample. Journal of Statistical Computation and Simulation 2013; 83(6): 1007-1019, http://dx.doi.org/10.1080/00949655.2011.647027.

11. Kundu D. Bayesian inference and life testing plan for the Weibull distribution in presence of progressive censoring. Quality Control \& Applied Statistics 2008; 54(2): 144-154, http://dx.doi.org/10.1198/004017008000000217.

12. Kundu D, Joarder. A analysis of type-II progressively hybrid censored data. Computational Statistics and Data Analysis 2006; 50: 25092528, http://dx.doi.org/10.1016/j.csda.2005.05.002.

13. Lieblein J, Zelen M. Statistical investigation of the fatigue life deep groove ball bearings. Journal of Research of the National Bureau of Standards 1956; 57: 273-316, http://dx.doi.org/10.6028/jres.057.033.

14. Murthy D N P, Xie M, Jiang R. Weibull models. New York: Wiley, 2003, http://dx.doi.org/10.1002/047147326X. 
15. Soland R. Bayesian analysis of the Weibull process with unknown scale and shape parameters. IEEE Transactions on Reliability Analysis 1969; 18: 181-184, http://dx.doi.org/10.1109/TR.1969.5216348.

16. Wang B X, Ye Z S. Inference on the Weibull distribution based on record values. Computational Statistics and Data Analysis 2015; 83: 26-36, http://dx.doi.org/10.1016/j.csda.2014.09.005.

17. Weibull W. A statistical distribution function of wide applicability. Appl. Mech 1951; 18: 293-297.

18. Zakerzadeh H, Jafari A A. Inference on the parameters of two Weibull distributions based on record values. Statistical Methods and Applications 2015; 24(1): 25-40, http://dx.doi.org/10.1007/s10260-014-0278-3.

Tiefeng ZHU

Department of Information Engineering

College of Youth Politics

Inner Mongolia Normal University

Hohhot 010051, P. R. China

\section{Zaizai YAN}

\section{Xiuyun PENG}

Science College

Inner Mongolia University of Technology

Hohhot 010051, P. R. China

E-mails: 2202432542@qq.com,

zz.yan@163.com,2009pxy@163.com 